\title{
EFFECT OF CARDBOARD SHELTER TRAPS ON PREDATION OF DIASPIDID SCALE INSECTS BY EUROPEAN EARWIGS, FORFICULA AURICULARIA, IN KIWIFRUIT
}

\author{
D.P. LOGAN ${ }^{1}$, B.J. MAHER ${ }^{1}$, P.G. CONNOLLY ${ }^{2}$ and M.J. PETTIGREW ${ }^{1}$ \\ ${ }^{1}$ HortResearch, 412 No. 1 Rd, Te Puke, New Zealand \\ ${ }^{2}$ HortResearch Private Bag 92 169, Auckland, New Zealand
}

Corresponding author: dlogan@hortresearch.co.nz

\begin{abstract}
European earwigs, Forficula auricularia L., are important predators of diaspidid scale insects in New Zealand kiwifruit. As European earwigs readily hide during the day in shelter traps made of corrugated cardboard strips rolled into cylinders, it may be possible to manipulate the level of scale predation. The effect of trapping duration on aggregation of earwigs and whether the addition of shelter traps to kiwifruit vine canopies led to increased numbers of earwigs and predation of scale insects were investigated. More earwigs were found in cardboard shelter traps exposed for up to 8 weeks than shorter periods. However, shelter traps were not associated with increased numbers of earwigs in vine canopies or with increased predation of scale insects. Predation of scale insects was 73-82\% and on individual canes depended on the initial density of scale. Further study is needed to realise the potential of earwigs as predators of scale insects and other pests.

Keywords: predation, diaspidid scale insects, kiwifruit, earwigs, shelter.
\end{abstract}

\section{INTRODUCTION}

The limited availability of new and selective insecticides and difficulties in importing new biological control agents into New Zealand means that existing insecticides and biological control need to be carefully managed to optimise pest management. Indigenous or established exotic generalist predators can suppress pests in a wide range of crops and have the advantage of persistence in the absence of pests and opportunistic feeding habits to exploit pest outbreaks (Symondson 2002). European earwigs, Forficula auricularia L., are generalist omnivores and are considered to be important natural enemies in apples under IFP and organic regimes in Europe, North America and Australia (Carroll \& Hoyt 1984a; Mueller et al. 1988; Nicholas et al. 2005). European earwigs have recently been identified as predators of diaspidid scale insects in New Zealand kiwifruit (Hill et al. 2005). Scale insects are the most important quarantine pests of kiwifruit exported to key Asian markets. Up to $40 \%$ of scale insects are eaten prior to harvest in autumn and this is mainly attributed to earwigs, which occur in the canopy of kiwifruit during summer and autumn (D.P. Logan \& B.J. Maher, unpubl. data).

Diaspidid scale insects are managed in kiwifruit orchards using a combination of organophosphate and mineral oil sprays supplemented by winter pruning to eliminate scale insect refugia in branch stubs and junctions. The most effective insecticides for scale control, diazinon and chlorpyrifos-based products, are not used by organic producers, but scale insects do not occur at significantly higher levels in organic than conventionally-managed kiwifruit (M.G. Hill, unpubl. data). Biological control by earwigs may contribute to suppressing scale insect infestation in organic blocks, but not in conventionally-managed blocks. This is at least partly because diazinon residues 
are highly toxic to earwigs and probably substantially reduce earwig populations in conventionally-managed kiwifruit (Maher et al. 2006). As European earwigs readily hide during the day in artificial shelter (Lamb \& Wellington 1974; Lamb 1975; Phillips 1981), manipulating the distribution of shelter in vines may influence local levels of earwigs and provide a means of managing scale insect predation. Carroll \& Hoyt (1984b) released European earwigs in an apple orchard in Washington, USA, after adding artificial shelter to trees and straw to the ground. Numbers of aphids on trees with shelter were reduced by a factor of 40 relative to control trees.

The objective of the work reported here was to determine whether providing artificial shelter in vine canopies would enhance local populations of earwigs and predation of scale insects by earwigs.

\section{General methods}

\section{METHODS}

All experiments relied on a standard form of artificial shelter trap for monitoring numbers of earwigs. The shelter traps were made of strips of corrugated cardboard (100 mm wide, $850 \mathrm{~mm}$ long) rolled into cylinders. Similar or identical traps have been used in studies of European earwigs elsewhere (Phillips 1981; Helsen et al. 1998; Burnip et al. 2002). The shelter traps were secured in the canopy of kiwifruit vines by means of a large wire staple, and protected from the weather by a plastic bag or an inverted waxed-paper milkshake container. Replicate observations were on individual vines, and treatments were assigned randomly to vines. Statistical analysis was completed in GenStat 9.1 or in R (R Development Core Team 2006). Significance for all statistical tests was $\mathrm{P}<0.05$.

\section{Occupation of shelter traps}

The effect of trapping duration on earwig occupation of shelter traps was studied in an organically-managed block of Actinidia chinensis cv. Hort16A kiwifruit. Treatments were eight trapping periods $(1,2,3,4,5,6,7$ and 8 weeks, starting from 27 November 2006), with ten vines per treatment and 80 vines in total. One shelter trap was secured in the canopy of each vine. Each week the 10 traps were removed, and earwigs in the traps were counted and released at the base of the same vine they were trapped in. The starting date for the study was based on phenology data for shelter traps left in vines for 1 -week periods that indicated that most earwigs were present in the kiwifruit canopy in December and numbers declined steadily after early January (D.P. Logan, unpubl. data). At the end of week 7 (15 January 2007), new traps were placed in vines used for treatment 1 ( 1 week duration) and emptied after 1 week coincident with counts for treatment 8 ( 8 weeks duration).

As data had a strong positive skew and means were correlated with the standard deviation, counts were transformed by $\log (\mathrm{x}+0.5)$ before analysis by one-way analysis of variance. Histograms and scatter plots of the residuals were examined to ensure that deviations were normally distributed and evenly spread across groups. Counts for traps exposed for 8 weeks from November and traps exposed for 1 week in January were compared by Mann-Whitney U test.

\section{Shelter traps and earwig abundance in vines}

The effect of shelter traps on the abundance of earwigs was determined by counting adults in the canopy of 30 vines in an organically-managed block of Hort 16A kiwifruit. The area of each vine sampled was standardised by counting earwigs in eight nonoverlapping $0.25 \mathrm{~m}^{2}$ quadrats located haphazardly along the main leader of each vine. Four shelter traps were secured to the top of the vine leader on 23 January 2007, and were at approximately equal distances from each other. Within each quadrat, pruning stubs and dead leaves ('natural shelter') were removed from the vine leader and adjacent canes, and destructively searched for earwigs on 28 February 2007. As an indirect measure of earwig presence, ten clear polycarbonate tubes $(5 \mathrm{ml})$ each with $1.2 \mathrm{~g}$ of general purpose insect diet (Singh 1983) were secured to the top of the leaders of all 30 vines on 20 February 2007. Clear tubes were selected to indicate feeding only, since 
Suckling et al. (2006) reported earwigs readily sheltered in covered diet tubes, but rarely sheltered in clear tubes. After 1 week, and 1 day prior to canopy quadrat sampling, the number of tubes with diet-coloured frass consistent with feeding by earwigs was recorded for each vine.

Counts of earwigs found in shelter traps and in natural shelter were first combined to provide an estimate of the total number of earwigs in the canopy of vines with traps. Numbers of earwigs for each vine were then square root transformed to remove a right skew in data before treatment means were compared by two-sample t-test. Proportions of tubes with frass were transformed by arcsine and means were compared for vines with and without shelter traps by a two-sample t-test.

\section{Effect of shelter on predation of scale insects}

The effect of shelter traps on predation rates of scale insects was determined for 30 mature female vines in an unsprayed block of Actinidia deliciosa cv. Hayward kiwifruit. Vines were randomly allocated to one of two treatments, 'with shelter traps' and 'without shelter traps'. Four shelter traps were placed equidistantly along the main leader of each of the 15 vines allocated to 'shelter trap' treatment on 2 November 2006. Canes extending from leaders were examined for adult scale insects on 26 October 2006. Single or groups of 2-10 scale insects were circled by permanent marker pen on four separate canes. Marked scale insects were within an area of approximately $100 \mathrm{~mm}$ of cane, and were often at the junction of two canes. Each single or group of marked scale insects was assumed to be independent of others as earwigs had a choice of at least 20 secondary branches and canes to search when travelling along the main leader. Marked scale insects were checked for predation after 1 week (2 November 2006) and then at 2 -week intervals until the last count on 24 January 2007. Scale insects were recorded as predated if part of or the whole wax cap was missing and the insect gone.

Predation appeared to be density-dependent, and data for vines with and without shelter traps were grouped according to the number of mature scale initially marked. Four groupings were used: 1, 2 or 3, 4 or 5, and 6-10. As all depletion of scale numbers was recorded as due to predation, censoring did not occur. Kaplan-Meier estimates of the survivor curves were compared using the non-parametric approximation to the chisquare distribution.

\section{Occupation of shelter traps}

\section{RESULTS}

Trapping duration from late November had an effect on the number of earwigs found in shelter traps $(\mathrm{P}=0.011)$, with a trend for more earwigs to be found in traps left for the longest periods (Fig. 1). Traps that were left in the canopy for 8 continuous weeks from late November had more earwigs (mean/trap $=5.5)$ than traps placed in the canopy for 1 week in mid-January $($ mean/trap $=0.8)(\mathrm{P}=0.017)$.

\section{Shelter traps and earwig abundance in vines}

There was no difference in the proportion of diet tubes with earwig frass pellets in vines with (back-transformed mean $=0.367$ ) and without (back-transformed mean $=0.333)$ shelter traps $(\mathrm{P}>0.05)$. The number of earwigs found in natural shelter (hollow pruning stubs, bark and dry leaves) in vines without shelter traps did not differ from combined trap and natural shelter counts for vines with shelter traps $(\mathrm{P}>0.05)$. For the 15 vines with shelter traps, there was no correlation between counts of earwigs in traps and those found in natural shelter in the same vine ( $\mathrm{P}>0.05)$ (Fig. 2).

\section{Effect of shelter on predation of scale insects}

Predation of marked scale insects on 24 January 2007 was $73 \%$ (initial total $=168$ scale insects) in vines without shelter traps and $82 \%$ (initial total $=162$ scale insects) on vines with shelter traps. There was no difference between Kaplan-Meier estimates of survival between scale insects on vines with and without shelter traps, irrespective of initial cluster size $(\mathrm{P}>0.05)$ (Fig. 3). 


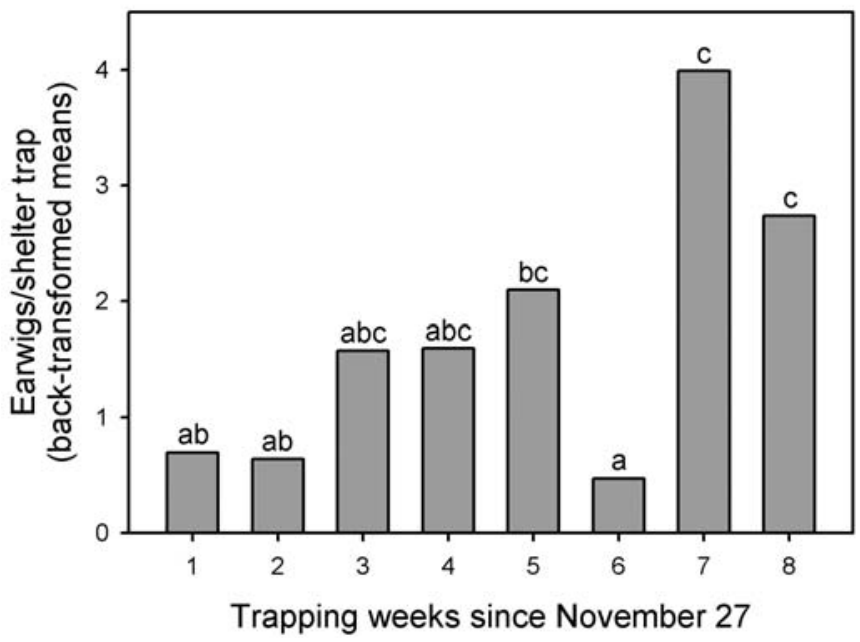

FIGURE 1: Number of earwigs in cardboard shelter traps left in the canopy of kiwifruit vines for 1-8 weeks. The same letters on the top of columns indicate groups within which there is no significant difference (LSD test at $\mathbf{P}<\mathbf{0 . 0 5}$ ).

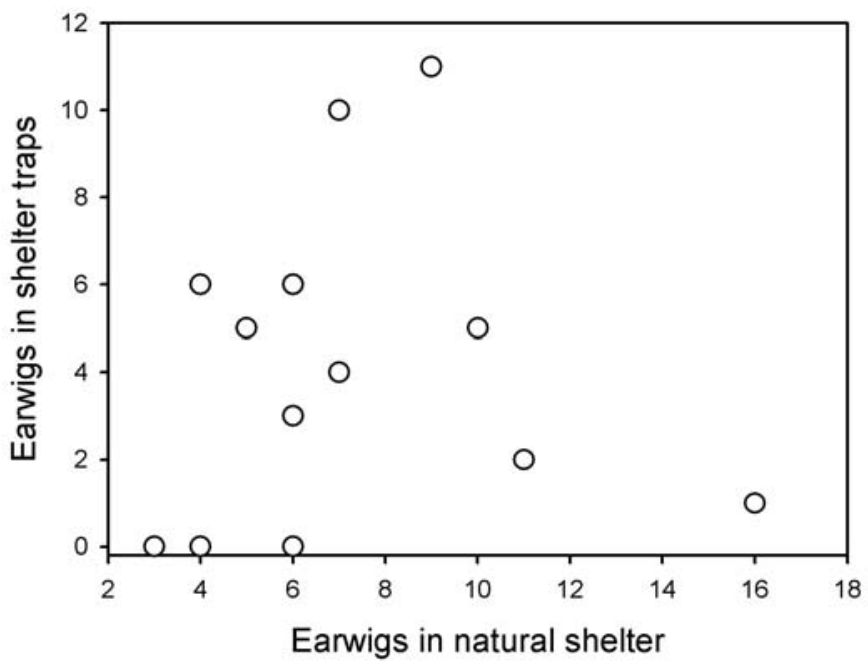

FIGURE 2: Scatter plot of the number of earwigs found in four cardboard shelter traps and in natural shelter (hollow pruning stubs, bark and dry leaves) in the same vine. 

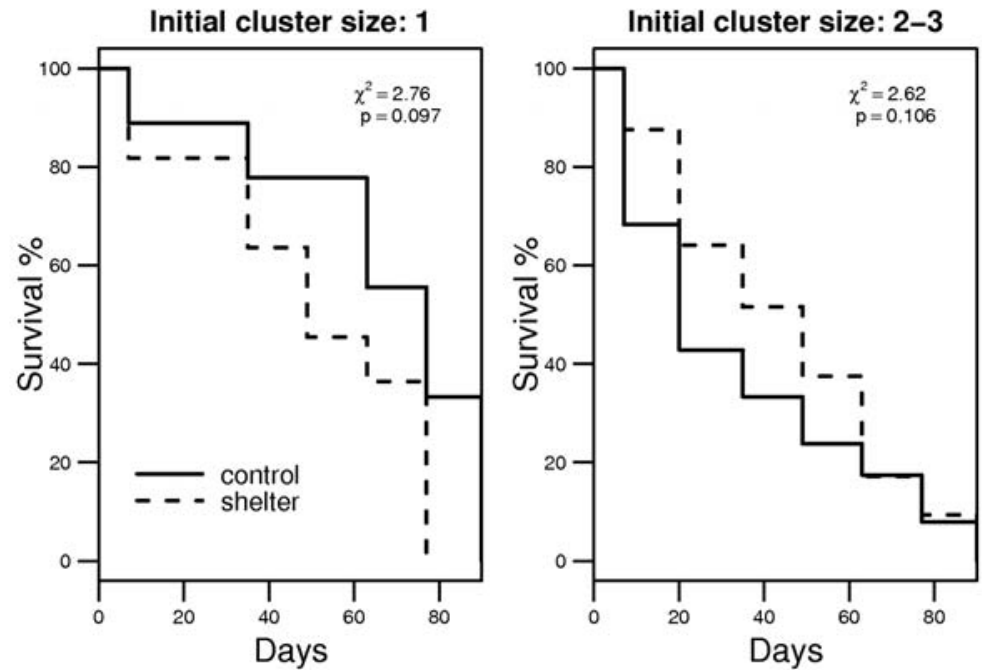

Initial cluster size: 4-5
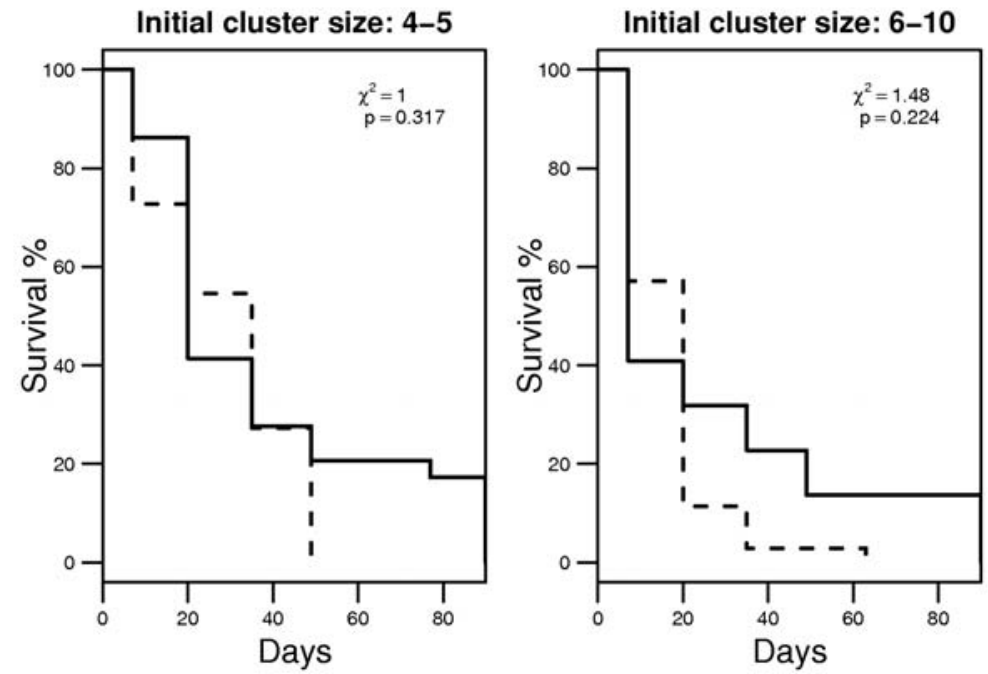

FIGURE 3: Kaplan-Meier survival curves for marked scale insects in vines with and without cardboard shelter traps. Scale insects were grouped according to initial density. 


\section{DISCUSSION}

The longer that earwig shelter traps remained in the canopy of kiwifruit vines, the more likely they were to contain higher numbers of earwigs. Similarly, Phillips (1981) found occupation by European earwigs of shelter traps increased over a 1-14 day period. The pattern of increasing trap occupation is unlikely to be an artefact of an increasing general population of earwigs. Studies of earwig phenology in groundcover and in the canopy of kiwifruit using shelter traps with 1-week catch periods indicated that populations reach a peak around mid-December and are declining in January (D.P. Logan, unpubl. data). The significant dip in trap catch at 6 weeks is without an explanation. Sprays (Bt) were applied to vines during the day on 7 December 2006 (during the second week of trapping) and on 2 January 2007, six days prior to trap counts at six weeks. As shelter traps were securely fastened to vine leaders and there was no evidence they were disturbed during the trapping period, it is unlikely that spray application was responsible for the low catch.

Increased use of artificial shelter over time by European earwigs may be related to accumulating deposits of male cuticular lipids that contain an aggregation compound (Walker et al. 1993). Lamb (1975) found that European earwigs preferred to shelter in traps that already had resident earwigs over traps that were empty and this may support the role of an aggregation pheromone. Use of artificial shelter is also related to the availability of food in the near vicinity. Lamb (1975) found that earwigs did not return to shelter when the local food supplies were exhausted. In kiwifruit, supplementary feeding of earwigs with pollen led to significant local increases in earwigs in shelter traps relative to adjacent vines (D.P. Logan, unpubl. data), but replication is needed to confirm the result. Occupation of artificial shelter may be reduced by the ready availability of adjacent natural shelter (Lamb 1975; Burnip et al. 2002). Trap catches of European earwigs were higher in sparse groundcover than in dense groundcover (Lamb 1975), and higher in herbicide-treated groundcover than in a groundcover of pea straw mulch (Burnip et al. 2002). In the present study, it is not clear that natural shelter was competing with cardboard shelter traps within the same vine canopy as there was no association between counts of earwigs in natural shelter and shelter traps. This may indicate that within a vine, earwigs do not have a preference for natural shelter over cardboard shelter traps. Further, it raises the question of whether individual vines are the most appropriate spatial unit for studies of earwigs in kiwifruit blocks.

A trapping duration effect may indicate increases of earwig populations in individual kiwifruit vines and this is potentially useful for manipulating biological control. However, in this study cardboard shelter traps did not influence the number of earwigs, their level of feeding activity, or the rate of predation of scale insects within individual kiwifruit vine canopies. Vines provide many natural shelter sites for earwigs in hollow pruning stubs, dead leaves, and to lesser extent, loose bark, and it is concluded that natural shelter in canopies is probably not limiting for earwigs in mature vines in mid-summer. European earwigs can shelter in the groundcover of orchards (Phillips 1981; Burnip et al. 2002), but we discounted groundcover as a significant source of earwigs for vine canopies because relatively few adult earwigs were found in searches and shelter traps at ground level in a kiwifruit orchard (D.P. Logan, unpubl. data).

Manipulative studies in which European earwigs are excluded from fruit-trees by sticky-bands indicate they may suppress pests by $50 \%$ or more even when they occur at densities as low as five per tree (Mueller et al. 1988; Solomon et al. 2000; Nicholas et al. 2005). However, studies of the effects of adding artificial shelter to fruit trees have met with mixed success (Carroll \& Hoyt 1984b; Carroll et al. 1985; Solomon et al. 2000). In kiwifruit at least it appears that there is sufficient natural shelter for earwigs, and additional artificial shelter for earwig encouragement is redundant. Further studies with artificial shelter as a method of monitoring populations are warranted, as are studies that focus on means other than use of artificial shelter to conserve and enhance populations of earwigs within a kiwifruit block. Supplementary food, increasing groundcover to provide greater arthropod prey abundance and diversity (e.g. Altieri \& Letourneau 1982; Rieux et al. 1999) and avoiding the application of insecticides that are toxic to earwigs 
may contribute significantly to earwig conservation. Density-dependent predation of scale insects is also an area for further study and may limit the contribution of earwigs in commercial orchards where scale populations are typically low.

\section{ACKNOWLEDGMENTS}

Funding for this study was provided by FRST through the programme C06X0301 Reducing Insecticide Risks. Mike Pettigrew's time was funded by an RSNZ teaching fellowship. Anne Barrington supplied the tubes of general purpose diet.

\section{REFERENCES}

Altieri MA, Letourneau DK 1982. Vegetation management and biological control in agroecosystems. Crop Protection 1: 405-430.

Burnip GM, Daly JM, Hackett JK, Suckling DM 2002. European earwig phenology and effect of understorey management on population estimation. New Zealand Plant Protection 55: 390-395.

Carroll DP, Hoyt SC 1984a. Augmentation of European earwigs (Dermaptera: Forficulidae) for biological control of apple aphid (Homoptera: Aphididae) in an apple orchard. Journal of Economic Entomology 77:738-740.

Carroll DP, Hoyt SC 1984b. Natural enemies and their effects on apple aphid colonies (Aphis pomi DeGeer) (Homoptera: Aphididae) on young apple trees in central Washington. Environmental Entomology 13: 469-481.

Carroll DP, Walker JTS, Hoyt SC 1985. European earwigs (Dermaptera: Forficulidae) fail to control apple aphid on bearing apple trees and woolly apple aphids (Homoptera: Aphididae) in apple rootstock stool beds. Journal of Economic Entomology 78: 972-974.

Helsen H, Vaal F, Blommers L 1998. Phenology of the common earwig Forficula auricularia L. (Dermaptera: Forficulidae) in an apple orchard. International Journal of Pest Management 44: 75-79.

Hill MG, Mauchline NA, Cate LR, Connolly PG 2005. A technique for measuring growth rate and survival of armoured scale insects. New Zealand Plant Protection 58: 288-293.

Lamb RJ, Wellington WG 1974. Techniques for studying the behavior and ecology of the European earwig Forficula auricularia (Dermaptera: Forficulidae). Canadian Entomologist 106: 881-888.

Lamb RJ 1975. Effects of dispersion, travel, and environmental heterogeneity on populations of the earwig Forficula auricularia L. Canadian Journal of Zoology 53: 1855-1867.

Maher BJ, Logan DP, Connolly PG 2006. Effect of mineral oil and diazinon residues on the predator European earwig, Forficula auricularia, in kiwifruit. New Zealand Plant Protection 59: 202-207.

Mueller TF, Blommers LHM, Mols PJM 1988. Earwig (Forficula auricularia) predation on the woolly apple aphid, Eriosoma lanigerum. Entomologia Experimentalis et Applicata 47: 145-152.

Nicholas AH, Spooner-Hart RN, Vickers RA 2005. Abundance and natural control of the woolly aphid Eriosoma lanigerum in an Australian apple orchard IPM program. BioControl 50: 271-291.

Phillips ML 1981. The ecology of the common earwig Forficula auricularia in apple orchards. PhD thesis, University of Bristol, UK.

R Development Core Team 2006. R: A language and environment for statistical computing. R Foundation for Statistical Computing, Vienna, Austria. ISBN 3900051-07-0, URL http://www.R-project.org

Rieux R, Simon S, Defrance H 1999. Role of hedgerows and ground cover management on arthropod populations in pear orchards. Agriculture, Ecosystems and Environment 73:119-127. 
Singh P 1983. A general purpose laboratory diet mixture for rearing insects. Insect Science and its Application 4: 357-362.

Solomon MG, Fitzgerald JD, Jolly R 1999. Artificial refuges and flowering plants to enhance predator populations in orchards. IOBC/WPRS Bulletin 22: 31-38.

Suckling DM, Burnip GM, Hackett J, Daly JC 2006. Frass sampling and baiting indicate European earwig (Forficula auricularia) foraging in orchards. Journal of Applied Entomology 130: 263-267.

Symondson WOC 2002. Can generalist predators be effective biocontrol agents? Annual Review of Entomology 47: 561-594.

Walker KA, Jones TH, Fell RD 1993. Pheromonal basis of aggregation in European earwig, Forficula auricularia L. (Dermaptera: Forficulidae). Journal of Chemical Ecology 19: 2029-2038. 